\title{
O PAPEL DO INSTITUTO NACIONAL DE PREVIDENCIA SOCIAL NOS ACIDENTES DO TRABALHO *
}

Pavésio, L. - O papel do Instituto Nacional de Previdência Social nos acidentes do trabalho. Rev. Saúde públ., S. Paulo, 7: 51-61, 1973.

Resumo: É descrita a maneira pela qual o Instituto Nacional de Previdência Social realiza a caracterização dos acidentes do trabalho, a investigação das suas causas, o pagamento de benefícios em casos de incapacidade temporária, incapacidade permanente e de morte, a assistência médica aos acidentados, a realibilitação profissional destes e a prevenção dos infortúnios profissionais. $E$ isto em decorrência da integração do seguro de acidentes do trabalho na previdência social, feita pela Lei n. ${ }^{\circ} 5316$, de 14 de setembro de 1967.

Unitermos: Acidentes de trabalho *; Previdência social *; Legislação *; Saúde ocupacional; Assistência médica; Acidentes (Prevenção).

A Lei n. 5.316 de 14 de setembro de 1967 consagra, de maneira definitiva a tese do monopólio estatal desse ramo de seguros, em seu artigo $1 .^{\circ}$ e parágrafo único, "in verbis":

"Art. $10^{\circ}-\mathrm{O}$ seguro obrigatório de acidentes do trabalho, de que trata 0 artigo 158, ítem XVII da Constituição Federal, será realizado na previdência social.

Parágrafo único: Entende-se como previdência social, para os fins desta Lei, o sistema de que trata a Lei n. 3.807 de 26 de agosto de 1960 , com as alterações decorrentes do Dec.lei n. 66 de 21 de novembro de $1966 . "$

Já o decreto-lei n. 7.036 de 10 de novembro de 1944, em seu artigo 111, vedava a concessão, a partir da vigência daquele diploma legal, a outras seguradoras particulares, para operar nesse ramo.

A nova legislação define:

"acidente do trabalho será aquele que ocorrer pelo exercício do trabalho, a serviço da emprêsa, provocando lesão corporal, perturbação funcional ou doença que cause a morte ou a perda ou redução, permanente ou temporária da capacidade para o trabalho".

Doença do trabalho será:

"qualquer das chamadas doenças profissionais, inerentes a determinados ramos de atividade e relacionadas em ato do Ministro do Trabalho e Previ-

\footnotetext{
* Trabalho apresentado à Disciplina de Saúde Ocupacional do Departamento de Saúde Ambiental da Faculdade de Saúde Pública da USP, em 1972.

* Do Hospital Santo Angelo - Mogi das Cruzes, S. P. - Brasil.
} 
PAVESIO, L. - O papel do Instituto Nacional de Previdência Social nos acidentes do trabalho. Rev. Saúde públ., S. Paulo, 7: 51-61, 1973.

dência Social, bem como a doença resultante das condições especiais ou exepcionais em que o trabalho for realizado, desde que diretamente relacionada com a atividade exercida (Decreto-lei $n .^{\circ} 893$ de 26/09/1969)".

Mesmo que o acidente não tenha sido a causa única, ele é considerado uma concausa, isto é, uma causa que concorre com outra para determinado fim. A causa propriamente dita, a traumática gera determinados defeitos e as concorrentes contribuem para que eles aconteçam.

As concausas podem ser:

a) preexistentes;

b) supervenientes $\mathbf{e}$

c) concamitantes.

São preexistentes quando antecedem o traumatismo. $O$ hemofílico pode falecer em consequiência de uma grave hemorragia, após um ligeiro traumatismo.

Ela é superveniente quando sucede ao acidente. Um pequeno acidente, infectado pelo tetano, pode causar a morte.

Será concomitante, quando ocorre simultaneamente com o acidente. Um desfalecimento que provoca uma queda pode ocasionar a fratura da base do crâneo, ocasionando a morte.

Será também considerado acidente do trabalho, nos termos do art. $3 .^{\circ}$ :

a) ato de sabotagem ou de terrorismo praticado por terceiro, inclusive companheiro de trabalho;

b) ofensa física intencional, inclusive de terceiro, por motivo de disputa relacionada com o trabalho;

c) ato de pessoa privada do uso da razão;

d) ato de imprudência ou negligência de terceiro, inclusive companheiro de trabalho;

e) desabamento, inundações ou incêndio;

f) outros casos fortuitos ou decorrentes de força maior;

Fora do local e do horário de trabalho, a lei qualifica como acidente do trabalho:

a) na execução de ordem ou na realização de serviço sob autoridade da empresa;

b) na prestação espontânea de qualquer serviço à empresa para lhe evitar prejuízo ou proporcionar proveito;

c) em viagem a serviço da empresa, seja qual for o meio de locomoção utilizado, inclusive veículo de propriedade do empregado;

d) no percurso da residência para o trabalho, deste para àquela .

Parágrafo único. Nos períodos destinados a refeições ou descanso, ou por ocasião da satisfação de outras necessidades fisiológicas, no local do trabalho ou durante este, o empregado será considerado a serviço da empresa.

Equipara-se ao acidente do trabalho, a doença do trabalho, e ao acidentado o trabalhador acometido de doença do trabalho (artigo $5^{\circ}$ ).

As doenças degenerativas ou inerentes a grupo etários, não são enquadradas na Lei.

Quando se trata de acidente é fácil determinar a data do início, o mesmo não ocorre com as doenças que evoluem lenta e progressivamente, admitindo-se como data do início a da comunicação dela à empresa.

$O$ acidente do trabalho, para ser bem compreendido e para que as normas que 
PAVtesio, L. - o papel do Instituto Nacional de Previdência Social nos acidentes do trabalho. Rev. Saúde públ., S. Paulo, 7: 51-61, 1973.

disciplinam a matéria possam ser fielmente interpretadas, deve ser situado, antes de tudo na sua verdadeira posição, como um evento de grande recuperação social.

Se não detivermos nossa atenção no reflexo que o acidente do trabalho provoca no seio do grupo humano, nós não poderemos perceber suas perspectivas mais profundas, não teremos como justificar os novos rumos abertos pelo legislador, não saberemos bem aplicar as suas leis, porque desconheceremos o espírito que as anima e não conseguiremos enfim, encontrar - na busca incessante de melhores normas para maior felicidade do homem - caminhos ainda ignorados.

Acidente é um vocábulo que indica um acontecimento que determina, fortuitamente, dano às pessoas e às coisas.

O seguro obrigatório de acidentes do trabalho tem em mira apenas o obreiro enfermo, mutilado, marginalizado pelo dano que sua atividade laborativa the causou. Os prejuizos materiais são cobertos por outras apólices de seguradoras particulares.

Se não houvesse leis que garantissem os acidentados e seus familiares, estariam sujeitos ao desemprego, ao marginalismo e à indigência, quando incapacitados.

A sociedade deve criar sistemas de segurança que garantam os meios de subsistência do indíviduo, quando privado da saúde.

A segurança social deve garantir a cada indíviduo, o necessário para uma vida digna, quando por motivo de força maior deixar de produzir.

O número alarmante e cada vez maior, de acidentes do trabalho no país, forçou o legislador a estabelecer normas disci- plinando a matéria, visando também previní-los.

Todo acidente é súbito, violento e fortuito, porque ocorre em um pequeno lapso de tempo, produz danos físicos e é involuntário.

Os prevencionistas conceituam acidente de trabalho como toda ocorrência inesperada, não programada que interfere com $o$ andamento normal do trabalho e da qual possa resultar lesão ao trabalhador.

Esse conceito enfatisa a perda de tempo e os prejuízos econômicos advindos do acidente, considerando as lesões como um fato ocasional.

São características patogênicas das doenças profissionais:

a) os sintomas devem aparecer, idênticos em vários trabalhadores que se dedicam a mesma profissão, no mesmo estabelecimento ou, preferentemente, para melhor conceituação do caráter profissional da moléstia, em estabelecimentos distintos;

b) deve ficar, claramente evidenciado que a moléstia tem como causa a atividade desenvolvida pelo trabalhador na empresa, seja pelas condições de serviço, seja pelos métodos empregados;

c) que a Lei as reconheça como tal.

\section{RESPONSABILIDADES DA EMPRESA}

Em caso de acidente do trabalho ou de doença do trabalho, a morte ou a perda ou redução da capacidade para 0 trabalho darão direito, independentemente de período de carência, às prestações previdenciárias cabiveis, concedidas, mantidas, pagas e reajustadas na forma e pelos prazos da legislação de previdência social.

A pensão será devida a contar da data do óbito, e o benefício por incapacidade, 
PAVrsio, L. - O papel do Instituto Nacional de Previdêncla Social nos acidentes do trabalho. Rev. Saude públ., s. Paulo, 7: 51-61, 1973.

do $16 .^{\circ}$ dia seguinte ao do acidente, cabendo à empresa pagar o salário integral do dia do acidente. A empresa contribuirá com $0,4 \%$ da folha de saláriode-contribuição dos empregados, se os riscos forem leves ou de $0,8 \%$ nos demais casos.

A empresa poderá responsabilizar-se apenas pelo pagamento do salário integral do dia do acidente, sendo o benefício por incapacidade devido, nessa hipótese, a contar do $10^{\circ}$ dia seguinte e a contribuição será de $0,5 \%$ ou de $1 \%$ da folha de salários-de-contribuição, conforme a natureza da atividade da empresa.

A empresa deverá, salvo em caso de impossibilidade absoluta, comunicar o acidente do trabalho à Previdência Social dentro de $24 \mathrm{hs}$., sob pena de uma multa variável de uma a 10 vezes o maior salário mínimo vigente no País.

O custeio das prestações por acidente do trabalho é da alçada exclusiva da empresa.

Quando as contribuições referidas são insuficientes para cobrir as despesas, o INPS é competente para estabelecer uma contribuição adicional até no valor de $25 \%$ do valor das contribuições já referidas, se as condiçōes de risco assim aconselharem.

A contribuição adicional será fixada: a) coletivamente, por classes, conforme a atividade da empresa; b) individualmente, por empresa, de acordo com a respectiva experiência ou condições de risco.

A relação das taxas correspondentes às diferentes atividades constituirá a tarifa das contribuições, para o custeio do seguro de acidente do trabalho, cuja fixação e revisão competem ao serviço atuarial. Será estabelecida e anualmente revista mediante proposta do INPS, em relação às diferentes atividades, com base na estatística referente ao triênio anterior.

A taxa de contribuição da empresa poderá ser alterada com base em suas condições de risco, quando estas sofrerem alteração apurada em inspeção.

A nova taxa não pođerá majorar nem reduzir a anterior de mais de $20 \%$. A inspeção será feita pelo INPS, de ofício ou a requerimento da empresa, e o relatório respectivo deverá conter o estudo do risco, aí incluídas as medidas de prevenção de acidentes e os dados previstos em laudo padronizado de inspeção do risco. A decisão do INPS será comunicada à empresa mediante notificação, sob registro postal, com recibo de volta ou quando possível, entregue diretamente, contra recibo.

As contribuiçōes referentes ao seguro de acidentes do trabalho serão recolhidas ao INPS juntamente com as da Previdência Social e nos mesmos prazos.

A empresa será obrigada a prestar ao INPS as informações e esclarecimentos necessários ao desempenho de suas atribuiçōes fiscalizadoras, inclusive permitindo visitas para inspeção de riscos.

A falta de oportuno recolhimento das contribuições sujeitará o responsável aos juros, multas, e correção monetária relativos ao débito. Nessas condições, não poderá ser fornecido pela Previdência Social certificado de regularidade de situação ou de quitação. Em caso de insolvência da empresa, os créditos previdenciários e securitários são privilegiados.

Nas localidades onde o INPS não dispuser de recursos próprios ou contratados, a empresa prestará ao acidentado assistência médica de emergência e, quando indispensável, a critério médico, providenciará sua remoção. $O$ INPS 
PAVESIO, L. - O papel do Instituto Nacional de Previdência Social nos acidentes do trabalho. Rev. Saúde públ., S. Paulo, 7: 51-61, 1973.

reembolsará a empresa das despesas dessa assistência até limites compatíveis com os padrões de local de atendimento.

\section{BENEFICIOS}

Os benefícios do INPS abrangem:

a) auxílio doença;

b) aposentadoria por invalidez;

c) pensão por morte;

d) auxilio acidente;

e) pecúlio;

f) abono especial previdenciário;

g) assistência médica e

h) reabilitação profissional.

São regidos pela Lei n. $5.326 / 67$ para os empregados urbanos e aos trabalhadores avulsos e pelo Decreto-lei n. 7.036/44, todos os empregados não abrangidos no regime geral da Previdência Social.

a) Auxilio doença: valor igual ao do salário de contribuição devido ao empregado no dia do acidente, deduzida a contribuição previdenciária $8 \%$, não podendo ser inferior ao seu salário de benefício (média aritmética dos 12 últimos salários de contribuição) com a mesma dedução. $O$ pagamento dos dias de benefício, quando a sua duração for inferior a um mês, será feito na base de 1/30 de seu valor mensal. Nenhum benefício por acidente do trabalho poderá ser inferior ao salário mínimo do local de trabalho do acidentado e nem superior a dez vezes este valor.

O direito ao auxílio doença, à aposentadoria por invalidez ou à pensão, exclui - direito aos mesmos benefícios nas condições da Lei Orgânica da Previdência Social.

O auxílio doença, à aposentadoria por invalidez e à pensão, dará direito também ao abono especial previdenciário.
O auxílio doença será devido ao acidentado que ficar incapacitado para o seu trabalho por mais de 15 dias. Será devido a contar do $160^{\circ}$ dia seguinte ao do acidente, cabendo à empresa pagar o salário integral do dia do acidente e dos 15 primeiros dias seguintes e será mantido enquanto o acidentado continuar incapaz para o seu trabalho. Se a empresa se responsabilizou apenas pelo salário integral do dia do acidente devido a sua tarifa de contribuição, 0 auxilio doença, nessa hipótese, será devido a contar do primeiro dia seguinte ao do acidente.

$O$ acidentado em gozo de benefício por incapacidade ficará obrigado, sob pena de suspensão do benefício, a submeter-se aos exames, tratamentos e processos de reabilitação profissional prescritos e proporcionados pelo INPS.

b) Aposentadoria por invalidez: valor mensal igual ao do salário de contribuição devido ao empregado no dia do acidente, não podendo ser inferior ao seu salário de benefício. Será majorado em $25 \%$ se, em consequiência do acidente, necessitar de assistência permanente de outra pessoa.

Terá direito à aposentadoria por incapacidade todo o acidentado que mediante avaliação da sua capacidade, obedecendo os critérios e tabelas estabelecidos pelo serviço Atuarial, apresentar uma redução superior a $60 \%$. Caberá à perícia médica determinar o grau e a extensão das lesóes e a relação técnica de causa e efeito entre o acidente $e$ a incapacidade.

c) Pensão por morte: Será igual ao do salário de contribuição devido ao acidentado no dia do acidente. Ela será devida aos dependentes do acidentado, a contar da data do óbito. Quando houver mais de um pensionista, a pensão será ratiada entre todos, em partes iguais. A 
PAVesio, L. - O papel do Instituto Nacional de Previdência Social nos acidentes do trabalho. Rev. Saude públ., S. Paulo, 7: 51-61, 1973.

cota daquele cujo direito à pensão cessar, reverterá em favor dos demais.

Quando a morte do acidentado aposentado por invalidez não resultar de acidente, o valor da aposentadoria vigente na data do óbito servirá de base para o cálculo da pensão.

d) Auxilio acidente: consistirá em uma renda mensal, reajustável na forma da legislação previdenciária e calculada na mesma percentagem da redução de capacidade, verificada sobre o valor do salário de contribuição devido ao acidentado no dia do acidente, não podendo ser inferior ao seu salário de benfício. Será devido ao acidentado que sofrer redução permanente da capacidade para o trabalho em percentagem superior a $25 \%$ e inferior a $60 \%$.

e) Pecúlio: consistirá em um pagamento único, cujo valor será calculado mediante aplicação da percentagem de redução da capacidade ao valor correspondente a 72 vezes o maior salário mínimo mensal vigente no País na data da autorização do pagamento. Será devido: $1.0^{\circ}$ ao acidentado com redução permanente da capacidade para o trabalho em percentagem igual ou inferior a $25 \%$; $\left.2 .^{\circ}\right)$ em caso de morte; $3 .^{\circ}$ ) em caso de invalidez, quando a aposentadoria prevividenciária for igual ou superior a $90 \%$ do salário de contribuição, no dia do acidente, não podendo ser inferior ao seu salário de benefício.

O pecúlio será devido, independentémente dos beneficios por incapacidade ou por morte, ao que o acidentado ou seus dependentes tiverem direito.

f) Abono especial de previdenciário: a importância será paga até o dia 15 de janeiro do exercício seguinte ao vencido e corresponde a $1 / 12$ do valor anual da aposentadoria ou pensão que o segurado ou seus dependentes tiverem percebido na respectiva Instituição. $O$ abono especial será devido aos aposentados e pensionistas, bem como aos segurados e aos dependentes que durante $o$ ano tiverem recebido auxílio doença por mais de 6 meses.

g) Assistência médica: prestada pelo INPS inclui a cirúrgica, a hospitalar, a farmacêutica e a odontológica, bem como o transporte do acidentado. Será devida, em caráter obrigatório, a partir da ocorrência do acidente.

Quando o acidentado, por motivos médicos, tiver de ser deslocado da localidade onde reside, sua remoção e hospedagem, bem como, quando indispensável, as de seu acompanhante, médico ou enfermeiro, ficarão a cargo do INPS.

Para prestação da assistência médica, - INPS poderá contratar serviços de terceiro, inclusive da própria empresa segurada, mediante convênio, com desconto, neste caso, em sua contribução referente ao seguro de acidente do trabalho, da percentagem que for fixada pelo serviço Atuarial.

h) Reabilitação profissional: quando a perda ou a redução da capacidade física puder ser atenuada pelo uso de aparelho de prótese, este será fornecido pelo INPS, independentemente das prestações cabíveis. Custeará ainda a reparação ou a substituição do aparelho desgastado pelo uso normal mediante pronunciamento prévio da autoridade técnica competente.

Para contrôle do custo e apuração dos resultados da assistência médica, reabilitação profissional e outros serviços prestados ao acidentado, o INPS manterá estatísticas, utilizando nomenclatura e classificação de serviços e de diagnósticos aprovados pelos órgãos competentes.

A Previdência Social promoverá a especialização de técnicos em perícia para avaliação da redução da capacidade 
PAVtisio, I. - O papel do Instituto Nacional de Previdéncia Social nos acidentes do trabalho. Rev. Saúde públ., S. Paulo, 7: 51-61, 1973.

para o trabalho e em reabilitação profissional de acidentados.

Ao acidentado com redução da capacidade para o trabalho que tiver condições de vir a exercer atividade remunerada, será proporcionado pelo INPS programa de reabilitação profissional.

Os auxílios materiais, como prótese, orteses, instrumentos de trabalho e medicamentos, bem como o custeio do transporte do acidentado, somente serão devidos quando prescritos por necessidades do processo de reabilitação.

O Decreto n. 71.037 de 29 de agosto de 1962, estabeleceu o procedimento administrativo para concessão dos benefícios decorrentes de acidente do trabalho, que reza em seu art. 1.:

"O acidentado, seus dependentes, a empresa ou qualquer outra pessoa somente poderão mover ação contra o INPS, diretamente ou por intermédio de advogado, depois de esgotada a via administrativa na Previdência Social".

Bastam alguns dados estatísticos, fornecidos pelo INPS, exercício de 1971, para ilustrar o pesado ônus que os acidentes do trabalho acarretaram à economia brasileira.

O número de acidentes registrados foi de 1.330.523. Cada um em média exigiu 16 dias de tratamento. Houve 157.397.848 horas perdidas. $O$ coeficiente de frequiência registrou 70,37 acidentes por cada milhão de homens horas trabalhadas.

Receberam simples assistência médica $-9,66 \%$.

Tiveram incapacidade temporária $87,02 \%$ e incapacidade permanente $3,13 \%$. Morreram - 0,19\%.

Em média ocorreram 4.405 acidentes por dia útil trabalhado.

\section{PREVENÇAO DE ACIDENTES}

Os enormes prejuízos causados à Nação pelo elevado número de acidentes, com tendência sempre a aumentar, obrigou o INPS a estabelecer programas de prevenção de acidentes, proporcionando assistência técnica à empresa, mediante:

a) programas específicos com vistas à adequada adaptação do empregado à atividade por ele exercida e ao ambiente e condições de trabalho;

b) formação de quadro de especialistas e de pessoal auxiliar;

c) colaboração na formação e aperfeiçoamento de pessoal da empresa na técnica de prevenção;

d) financiamento para a instalação de equipamento e a adoção de processos ou medidas técnicas destinadas à melhor proteção ao empregado;

e) assessoramento para elaboração e desenvolvimento de programas de prevenção, inclusive mediante acompanhamento e orientação das atividades da Comissão Interna de Prevenção de Acidentes (CIPA);

f) utilização de recursos técnicos de terceiros para desenvolvimento de programas de prevenção;

g) estabelecimento de incentivos a programas de prevenção;

h) cooperação com o Departamento Nacional de Segurança e Higiene do Trabalho (DNSHT) e com entidades interessadas, na elaboração de normas técnicas de prevenção;

i) realização de pesquisas e estudos sobre ambientes e condições de trabalho, com vistas à diminuição do risco de acidentes.

O INPS poderá conceder financiamento especial à empresa, para facilitar a ins- 
PAVÉSIO, L. - O papel do Instituto Nacional de Previdência Social nos acidentes do trabalho. Rev. Saúde públ., S. Paulo, 7: 51-61, 1973.

talação de equipamento e a adoção de processos destinados a assegurar melhor proteção ao empregado.

O financiamento obedecerá as normas que forem expedidas pelo DNSHT, por proposta do INPS e ouvido o serviço Atuarial. Somente serão concedidos para instalações e equipamentos que, a critério do INPS, concorram diretamente para a melhoria das condições de risco, não podendo ser financiadas despesas que tenham apenas relações remotas com esse objetivo.

O INPS poderá auxiliar, mediante assistência técnica, entidades de fins não lucrativos que desenvolvam atividades de prevenção de acidente e de reabilitação profissional, bem como de segurança, higiene e medicina do trabalho.

A contribuição para a Fundação Centro Nacional de Segurança, Higiene e Medicina do Trabalho (Fundacentro) será de $0,5 \%$ do produto da contribuição básica da folha de salários de contribuição dos empregados da empresa.

A empresa, além dos objetivos econômicos, deve se preocupar com a segurança e o bem estar social e moral dos seus colaboradores.

Toda estrutura operacional da empresa, em todos os seus escalōes devem estar alertas com os riscos de acidentes e doenças, buscando soluções satisfatórias, amenizando-os e, sempre que possível, eliminando-os.

As normas técnicas da Consolidação das Leis do Trabalho (CLT) e das legislações complementares aprovadas por decretos, portarias ministeriais e portarias do DNSHT devem ser rigorosamente cumpridas. Caso o empresário não tenha condições técnicas de organizar, de projetar ou executar os programas, poderá contratar os serviços de organizações especializadas na matéria. A Fundacentro presta esses serviços.

O empresário ao adquirir máquinas, equipamentos, ferramentas, e outros instrumentos de trabalho necessários, deverá levar em conta, além do preço, qualidade e produtividade, quais os perigos que eles oferecem ao trabalhador exposto e se há meios seguros de evitá-los.

Os sistemas de proteção coletiva quando necessários, devem ser projetados por pessoas técnicas especializadas para que sejam adequados às suas finalidades $e$ comprovadamente eficazes.

Os equipamentos de proteção inđividual devem obedecer os padrões recomendados pelo DNSHT e usados sempre que necessários devido ao risco de acidentes.

$$
\text { CIPA - "COMISSAO INTERNA DE }
$$$$
\text { "PREVENÇÃO DE ACIDENTES" }
$$

Por força do que dispõe o Artigo 164 da CLT: "As empresas que, a critério da autoridade competente em matéria de segurança e higiene do trabalho, estiverem enquadradas em condições estabelecidas nas normas expedidas pelo Departamento Nacional de Segurança e Higiene do Trabalho, deverão manter, obrigatoriamente, serviço especializado em segurança e higiene do trabalho e constituir comissões internas de prevenção de acidentes (CIPA)".

Elas são regulamentadas pela Portaria n. 32 de 19/11/1968 do DNSHT, e, de acordo com tal documento legal, devem existir em todas as empresas industriais, comerciais e de transportes marítimos, fluviais, aéreos e terrestres onde trabalham cem ou mais empregados.

Sempre que houver um acidente na indústria, o encarregado do setor deverá preencher um relatório minucioso da ocorrência. 
PAVESIO, I. - O papel do Instituto Nacional de Previdência Social nos acidentes do trabalho. Rev. Saúde públ., S. Paulo, 7: 51-61, 1973.

\section{Dados Iniciais}

Identificação, função, local dia e hora do acidente.

2. Operação

a) - denominação da operação:

Deverá ser indicada a operação ou sẹrviço que estava sendo executado pelo acidentado, circunstanciando o local de trabalho. Para maior clareza pode se juntar um croquis para ilustrar melhor o acidente como ocorreu.

b) - descrição minuciosa da operação:

Permitindo compreender o processo de operação, analisando detidamente os riscos que ela oferece e principalmente o causador do acidente.

\section{Conceituação do risco}

a) - condições inseguras:

Levantamento local de todos os agentes que oferecem riscos: instalações, pisos, iliminação, poeiras, calor, ordem, limpeza.

No caso de doenças profissionais os riscos decorrentes de agentes físicos, biológicos e químicos merecem especial atenção.

b) - atos inseguros:

Análise detalhada do compartamento do acidentado quando houve a ocorrência. Dosar qual foi a sua responsabilidade. Registrar se o trabalho realizado naquele momento era normal, ocasional ou excepcional. Se o mesmo deixou de usar os meios de proteção disponíveis. Se decorreu por ação de terceiro: brigas, brincadeiras etc..

\section{Descrição minuciosa do risco}

Esmiuçar o risco que deu origem ao acidente investigado, descrevendo-o da forma objetiva evitando descrição genérica, para que se compreenda e se conclua da verdadeira causa ou concausa do acidente, verificando se a máquina e os equipamentos estavam protegidos. $\mathbf{E}$ se protegidos, qual o grau de eficiência.

Ao médico caberá a descrição das lesões, apurando o grau de incapacidade ou doença.

Com todos esses dados, a CIPA se reuniará e analisará a ocorrência, tirando conclusões e propondo recomendações ao empregador, visando eliminar os riscos e ordenar sanções aos culpados.

Na reunião mensal da CIPA todos os casos de acidentes ocorridos e registrados deverão ser levantados estatisticamente e relacionados a um milhão de homens horas trabalhadas.

Dois indices estatísticos, aceitos por convenção internacional, permitem por comparação avaliar se os coeficientes estão elevados ou abaixo da média, em relação a outras indústrias congêneres: coeficiente de frequiência e de graviđade.

$O$ coeficiente de frequiência expressa $O$ número de acidentes com perda de tempo por um milhão de homens-horas trabalhadas.

O coeficiente de gravidade diz do número de dias perdidos e dias debitados por um milhão de homens-horas trabalhadas.

Por definição entende-se por dias perdidos, o número de dias durante os quais o acidentado permaneceu afastado do trabalho, excluindo o dia do acidente.

Os dias debitados são fornecidos por tabelas estabelecidas empiricamente, em convenção internacional (DNSHT-32 de 19/11/1968).

O trabalho da CIPA é um trabalho de equipe, em que os seus membros são os coordenadores e todos os demais integrantes da indústria, membros natos, participantes e ativos na prevenção de acidentes. 
PAVÉSIO, I. - O papel do Instituto Nacional de Previdência Social nos acidentes do trabalho. Rev. Saúde públ., S. Paulo, 7: 51-61, 1973.

Cópias das atas das reuniões deverão ser encaminhadas às Delegacias Regionais do Trabalho, nos limites de suas respectivas jurisdições, que fornecerão certificados referentes ao cumprimento das obrigações.

\section{CUSTOS DO ACIDENTE}

Devem ser avaliados os diretos e os indiretos.

Os diretos são estabelecidos por Lei nos termos do artigo 12 da Lei n.' 5.316 de 14 de setembro de 1967. Caberá ao INPS pagar os benefícios, decorrentes do acidente, nos termos da mesma Lei.

Os custos indiretos são muitos variáveis, dependendo de inúmeros fatores, sendo os principais:

a) manutenção de um pronto socorro, equipado com pessoal e material adequado;

b) perda de tempo com queda de produção na quantidade e, às vezes, na qualidade; c) elevação de despesas extraordinárias para compensar os prejuizos acarretados, etc..

Normalmente, o custo dos acidentes indiretos supera de três a quatro vezes os custos diretos, embora nem sempre seja isso percebido pelo empregador.

No ano de 1971 o INPS dispendeu a quantia total de Cr $\$ 679.055 .858,00$, assim distribuída: benefícios, $43,04 \%$; serviços de assistência médica e reabilitação, $19,64 \%$; prevenção de acidentes, $0,19 \%$; administração, $2,19 \%$; provisões para benefícios de longa duração e acidentes não liquidados, $26,52 \%$.

A despesa correspondeu a $91,58 \%$ da receita que deu o montante de

Cr\$ 741.455.558,00.

A grandeza destes valores justifica plenamente as medidas legais tomadas pelo Governo, procurando tecnicamente disciplinar as empresas, na prevenção dos acidentes.

PAVÉSIO, L. - [The National Institute of Social Welfare and occupational accidents.] Rev. Saúde públ., S. Paulo, 7: , 1973.

Summary: It is related the manner by which the National Institute of Social Welfare realizes the characterization of the occupational accidents, the investigations of their causes, the payment of benefits in occurence of temporary incapacity, permanent incapacity and death, the medical care to the injureds, their professional rehabilitation and the professional misfortune prevention. And this due to the integration of the occupational accidents in the social welfare, brazilian law $n .^{\circ} 5316$, of September 14, 1967.

UNITERMS: Accidents, accupational *; Social welfare *; Legislation *; Occupational health; Accidents, industrial; Accidents, prevention; Medical care. 
PAVesio, L. - O papel do Instituto Nacional de Previdência Social nos acidentes do trabalho. Rev. Saude puibl., S. Paulo, 7: 51-61, 1973.

LEGISLACAO QUE SFRVIU DE BASE PARA O TRABALHO

DECRETO-LEI $n .^{\circ} \mathbf{5 . 4 5 2}$ de $1 .^{\circ}$ de maio de 1943: aprova a consolidação das Leis do Trabalho. Diário Oficial da União, 9 maio 1943.

LEI n. 5.316 de 14 de setembro de 1967: integra o seguro de acidentes do trabalho na Previdência Social e dá outras providências. Diârio Oficial da União,
18 setembro 1967. p. 9527.

DECRETO n. 61.784 de 28 de novembro de 1967: aprova o Regulamento do seguro de Acidentes do Trabalho. Diário Oficial da União, 29 novembro 1967.

DECRETO-LEI n. 71.037 de 29 de agosto de 1972: estabelece o procedimento administrativo para concessão dos benefícios decorrentes de acidente do trabalho.

Recebido para publicação em 8/12/1972

Aprovado para publicação em 29/1/1973 